\title{
A Risk Assessment Methodology in Container Terminals: The Case Study of the Port Container Terminal of Thessalonica, Greece
}

\author{
Constantinos I. Chlomoudis, Petros L. Pallis and Ernestos S. Tzannatos \\ Department of Maritime Studies, University of Piraeus, Piraeus 18532, Greece
}

\begin{abstract}
Amidst the ever increasing demand for the unhindered flow of freight throughout the world, seaport safety is emerging as a critical factor which increasingly dictates the need to establish a proactive approach towards addressing the associated risks rather than the traditional reactive response to port accidents. This paper proposes and presents a proactive methodology for port safety risk assessment (including the techno-economically effective prioritized control) which constitutes an adaptation of the FSA (Formal Safety Assessment) for ships. The ability of the proposed methodology to offer this standardized approach for PRA (Port Risk Assessment) is demonstrated through reference to the container terminal of the Greek Port of Thessalonica, for which an empirical study is contacted utilizing the historical record of encountered accidents with regard to their frequency of occurrence and their impact upon the human and environmental resources of the port.
\end{abstract}

Key words: Ports, risk assessment, container terminals, case study, Greece.

\section{Introduction}

A great variety of activities are performed in port terminals: transport of passengers; transport of cargo; storage of oil and chemicals; storage and transport of cars; traffic of ships, trucks and trains, etc. Due to this intense activity, ports are very important facilities for the economy of a country [8], but also "a place of risk", where harm can be directed to persons (crew/passengers/others), environment (nature) and/or property, i.e., ships/port facilities/other [4]. The port industry is one of the business sectors facing significant threats, which increase the risk taken by both investors and stakeholders in general. Managing such risks is an object of research [2]. Managers incorporate risk analysis in their decision-making process and the adaptations of risk analysis and management by maritime discipline, along with its deployment in the port industry and government agencies in decision-making [3] have led to an

Correspondent author: Petros L. Pallis, Ph.D. candidate, research fields: port management and risk management. unprecedented development of theory, methodology, and practical tools [5].

It is evident that although attempts to assess safety in ports have been identified throughout port development, the need to employ risk assessment methods and techniques has only recently been clearly distinguished. A risk-based methodology can be integrated into day-to-day management and risk quantification can be used in the later stage either to optimize the management of safety, and or to facilitate other decision making processes [10]. On the other hand, as there is no specific risk assessment method or framework to cope with safety risks in general and ports in particular, this paper proposes an approach for risk assessment in container terminals which constitutes an adaptation of the IMO (International Maritime Organization) FSA (Formal Safety Assessment) [11]. Described as "a rational and systematic process for assessing the risks associated with shipping activity and for evaluating the costs and benefits of IMO's options for reducing these risks", the FSA through its risk-based approach is distinct in 
adopting a proactive approach towards the facilitation of the rule-making on ship safety at IMO level.

Similar to the structure of the FSA as applied to the safety risks of ships, the proposed PRA (Port Risk Assessment) is based on the evaluation of risks relevant to ports and the analysis of their effective control through combining the economic and risk reducing influence of alternative RCO (Risk Control Options). By virtue of its significance, the container terminal of the Greek Port of Thessalonica presents a suitable reference for demonstrating the applicability of the proposed PRA methodology, through contacting an empirical study on encountered accidents during 2008 2011. The results indicate that the PRA offers a workable methodology for the application of safety risk assessment in ports, whilst the conclusions drawn provide a firm basis for further research on this issue.

\section{PRA Methodology}

\subsection{Port Risk Assessment}

The PRA maintains the basic number and feature of the steps involved in the structure of the FSA and differs with regard to the content of the steps, as presented in Table 1 .

\subsection{Risk Identification}

With the port being identified as the system of interest, risk identification is the first and in many ways the most important step in risk assessment. An overlooked risk is likely to introduce more error into the overall risk estimate than an inaccurate consequence model or frequency estimate. Therefore, the aim of risk identification is to produce a comprehensive list of all risks [10]. The usual approach to risk identification which is found in the FSA and supply chain risk literature, and is also described by industry stakeholders, is to try to list all conceivable risks, sometimes helped by a source categorization. Investigating historical data on previous incidents is typically the first step, in addition to structured brainstorming sections with practitioners for conceivable risks [1]. Our risk identification technique utilizing existing literature and practitioners' experience in order to focus on the risks associated with the specialized system of ports and container terminals. The taxonomy of risks in port container terminals is shown in Fig. 1, according to which five main risk categories are subdivided into numerous sub-categories.

\subsection{Risk Assessment}

Risk can be quantitatively and qualitatively assessed by the use of a risk matrix in which the rows represent the increasing severity of consequences of a released risk and the columns represent the increasing likelihood or frequency of these consequences. The quantification of the risk is performed through the summation of frequency (FI) and severity (SI) indices which express various levels of corresponding significance, as shown in Tables 2 and 3, respectively.

For each risk, one or several "barriers" can be specified to prevent or minimize the likelihood of risk release. For any barrier there may be internal or external factors which affect its effectiveness. These factors or barrier failure modes can be modeled as "escalation factors" each of which can be controlled

Table 1 Structure of PRA.

\begin{tabular}{lll}
\hline Step & Step feature & Step content \\
\hline 0 & System identification & Port; container terminal \\
1 & Risk identification & What may go wrong and which port functions/capabilities should be protected \\
2 & Risk assessment & Investigation/quantification of most important port risks \\
3 & Risk control options & Measures to mitigate most important port risks and measures to restore port functions/capabilities \\
4 & Cost/benefit assessment & Cost/benefit assessment of port risk control measures \\
5 & Decision making & Recommendation and feedback to assessment - port risk index \\
\hline
\end{tabular}

Source: Authors. 


\begin{tabular}{|c|c|}
\hline Risk categories & Risk sub-categories \\
\hline \multirow{9}{*}{ Human } & Ship collisions \\
\hline & Grounding \\
\hline & Sinking \\
\hline & Navigation error \\
\hline & Pilotage error \\
\hline & Poor maintenance \\
\hline & Falling of a crane \\
\hline & Falling of a container \\
\hline & Error in cargo handling and storage \\
\hline \multirow{4}{*}{ Machinery } & Damage to equipment \\
\hline & Fire/explosion \\
\hline & Machinery failure \\
\hline & System failure \\
\hline \multirow{9}{*}{ Environment } & Ships emissions \\
\hline & Dredging \\
\hline & Oil spills \\
\hline & Chemical contaminants \\
\hline & Ballast waters \\
\hline & Ship breaking/salvage activities \\
\hline & Air toxics \\
\hline & Noise pollution \\
\hline & Alien species \\
\hline \multirow{8}{*}{ Security } & War/political instability \\
\hline & Terrorist \\
\hline & Theft \\
\hline & Smuggling \\
\hline & Illegal trade \\
\hline & Vandalism \\
\hline & Illegal immigration \\
\hline & Blockade \\
\hline \multirow{8}{*}{ Natural } & Earthquakes \\
\hline & Volcanic eruptions \\
\hline & Hurricane \\
\hline & Strong winds \\
\hline & Heavy swell and sea \\
\hline & Floods \\
\hline & High temperature during working hours \\
\hline & Heavy rain \\
\hline
\end{tabular}

Fig. 1 Taxonomy of risks in port container terminals. Source: [4].

by "escalation factor control". These escalation factor controls can be envisaged as secondary barriers. Any risk should have a sufficient number of barriers and escalation factor controls to ensure the integrity of the risk assessment.

\subsection{RCO (Risk Control Options)}

The purpose of this step is to propose economically effective RCOs (Risk Control Options). The basic task is to group risk control measures into possible RCOs. Useful tools in the identification of possible risk reduction measures are the development of causal chains or the development of risk contribution diagrams, using fault trees or event trees diagrams. The areas that have to be focused, are those related to high frequencies or high consequences, where the risk is intolerable. Risk control measures, through expert meetings and decisions, are combined into potential RCOs. The criteria of grouping can vary, can be just the decision of the experts or can be the fact that risk control measures prevent the system from the same failure or type of accident. The grouping of risk control measures is very important and more important is the grouping of RCOs. The outcome of this step is a list of RCOs that will be analyzed in the next step for their cost and benefit effectiveness. Moreover, the risk reduction $(\Delta R)$ of an $\mathrm{RCO}$ is a very important parameter, because it provides a measure of the risk control obtained by each RCO, which can either reduce the risk to the acceptable level or can provide an even higher reduction rate.

\subsection{RCO Economic Effectiveness}

The economic effectiveness of each $\mathrm{RCO}$ is evaluated based upon: (1) the NPV (net present value) cost of its implementation and operation (including maintenance) through its lifetime $(\Delta C)$; and (2) its risk reduction $(\Delta R)$ over the same period. Depending on the nature of risks addressed, the RCO acceptance and prioritization is weighed against the ICAF (implied cost of averting a fatality) or the CATS (cost of averting a tonne of oil spilled). Although many proposals exist for appropriate optimum values of ICAF, no universally accepted values that are currently established. However, the value of $\$ 3$ million as suggested 
Table 2 FI (frequency index).

\begin{tabular}{llll}
\hline FI & Frequency & Definition & F (per year) \\
\hline 7 & Frequent & Likely to occur once per day & 10 \\
5 & Reasonable possible & Likely to occur once per month & 1 \\
3 & Remote & Likely to occur once per year & 0.1 \\
1 & Extremely remote & Likely to occur once in a life time & 0.01 \\
\hline
\end{tabular}

Source: Adapted by IMO FSA.

Table 3 SI (severity index).

\begin{tabular}{|c|c|c|c|c|c|}
\hline SI & Severity & Effects on human safety & $\begin{array}{l}\text { Effects on equipment or } \\
\text { infrastructure }\end{array}$ & Effects on environment & $\begin{array}{l}\text { S (equivalent } \\
\text { fatalities) }\end{array}$ \\
\hline 1 & Minor & Single or minor injuries & Local equipment damage & Local environmental damage & 0.01 \\
\hline 2 & Significant & Multiple or severe injuries & $\begin{array}{l}\text { Non severe equipment or } \\
\text { infrastructure damage }\end{array}$ & $\begin{array}{l}\text { Non severe Local } \\
\text { environmental damage }\end{array}$ & 0.1 \\
\hline 3 & Severe & $\begin{array}{l}\text { Single fatality or multiple } \\
\text { severe injuries }\end{array}$ & $\begin{array}{l}\text { Severe equipment or } \\
\text { infrastructure damage }\end{array}$ & $\begin{array}{l}\text { Severe local environmental } \\
\text { damage }\end{array}$ & 1 \\
\hline 4 & Catastrophic & Multiple fatalities & Total loss & $\begin{array}{l}\text { Catastrophic extended } \\
\text { environmental damage }\end{array}$ & 10 \\
\hline
\end{tabular}

Source: Adapted by IMO FSA.

for use by IMO continues to be a valid proposal [9]. Furthermore, Skjong et al. [9], Vanem et al. [12, 13] and Psarros et al. [7] presented an environmental criterion equivalent to ICAF which assesses the RCO's economic effectiveness towards the prevention of accidental releases of oil to the marine environment. This criterion was named CATS and its suggested threshold value was $\$ 60,000$ per ton. A specific RCO for reducing environmental risk should be recommended for adoption provided its $\Delta C / \Delta R$ value is below that of CATS, otherwise that particular RCO should not be recommended [6, 14]. Therefore for RCO acceptance and prioritization, the expression $\mathrm{ICAF} \leq \Delta C / \Delta R$ and $\mathrm{CATS} \leq \Delta C / \Delta R$ applies with regard to risks of human and environmental consequences, respectively.

\subsection{Decision Making}

The recommendations for decision making should be a synthesis of the previous steps, selecting which measures to include and the identification of those RCOs which keep risks as low as reasonable practicable. We suggest that both individual and societal types of risk should be considered for all port stakeholders, in the direction of creating a port risk indicator, with objective acceptable or non acceptable regions. In that way, all ports could be ranked, benchmarking themselves based on quantification of their risk level. Subsequently, port managers and marketers would invest in their port's ALARP (as low as reasonable practicable) reputation, in order to attract potential customers.

\section{PRA Case Study: Thessalonica Container Terminal}

\subsection{Risk Assessment}

In an effort to demonstrate the validity of the proposed PRA through a workable example, we obtained the historical data (2008 2011) of incidents involving human and environmental damages in the container terminal of Thessalonica, as shown in Table 4.

By scaling all human injuries to single fatalities according to the severity equivalence (S) shown in Table 4 , the fatality rate at the container terminal of Thessalonica over the period 2008 2011 is found to be equal to 0.9825 fatalities per port-year. In terms of the environmental damage at the container terminal of Thessalonica over the period 2008 2011, there were three incidents, regarding oil and chemical spills of 
Table 4 Human damage (2008 2011).

\begin{tabular}{|c|c|c|c|c|c|c|}
\hline Month & Injury severity & 2008 & 2009 & 2010 & 2011 & Total \\
\hline \multirow{4}{*}{ January } & Minor & 0 & 0 & 0 & 0 & 0 \\
\hline & Significant & 0 & 0 & 1 & 0 & 1 \\
\hline & Single fatality & 0 & 0 & 0 & 0 & 0 \\
\hline & Total & 0 & 0 & 1 & 0 & 1 \\
\hline \multirow{4}{*}{ February } & Minor & 1 & 0 & 0 & 0 & 1 \\
\hline & Significant & 0 & 0 & 1 & 0 & 1 \\
\hline & Single fatality & 0 & 0 & 0 & 0 & 0 \\
\hline & Total & 1 & 0 & 1 & 0 & 2 \\
\hline \multirow{4}{*}{ March } & Minor & 0 & 0 & 0 & 0 & 0 \\
\hline & Significant & 1 & 0 & 0 & 1 & 2 \\
\hline & Single fatality & 0 & 0 & 0 & 0 & 0 \\
\hline & Total & 1 & 0 & 0 & 1 & 2 \\
\hline \multirow{4}{*}{ April } & Minor & 1 & 0 & 0 & 1 & 2 \\
\hline & Significant & 0 & 0 & 0 & 0 & 0 \\
\hline & Single fatality & 0 & 0 & 0 & 0 & 0 \\
\hline & Total & 1 & 0 & 0 & 1 & 2 \\
\hline \multirow{4}{*}{ May } & Minor & 0 & 1 & 0 & 1 & 2 \\
\hline & Significant & 0 & 0 & 0 & 0 & 0 \\
\hline & Single fatality & 0 & 0 & 0 & 0 & 0 \\
\hline & Total & 0 & 1 & 0 & 1 & 2 \\
\hline \multirow{4}{*}{ June } & Minor & 1 & 0 & 1 & 0 & 2 \\
\hline & Significant & 0 & 0 & 0 & 0 & 0 \\
\hline & Single fatality & 0 & 0 & 0 & 0 & 0 \\
\hline & Total & 1 & 0 & 1 & 0 & 2 \\
\hline \multirow{4}{*}{ July } & Minor & 0 & 1 & 1 & 0 & 2 \\
\hline & Significant & 0 & 0 & 0 & 1 & 1 \\
\hline & Single fatality & 0 & 0 & 0 & 0 & 0 \\
\hline & Total & 0 & 1 & 1 & 1 & 3 \\
\hline \multirow{4}{*}{ August } & Minor & 0 & 0 & 1 & 0 & 1 \\
\hline & Significant & 1 & 0 & 0 & 0 & 1 \\
\hline & Single fatality & 0 & 0 & 0 & 0 & 0 \\
\hline & Total & 1 & 0 & 1 & 0 & 2 \\
\hline \multirow{4}{*}{ September } & Minor & 0 & 0 & 0 & 0 & 0 \\
\hline & Significant & 0 & 0 & 1 & 0 & 1 \\
\hline & Single fatality & 1 & 0 & 0 & 0 & 1 \\
\hline & Total & 1 & 0 & 1 & 0 & 2 \\
\hline \multirow{4}{*}{ October } & Minor & 1 & 1 & 0 & 1 & 3 \\
\hline & Significant & 0 & 0 & 0 & 0 & 0 \\
\hline & Single fatality & 0 & 0 & 0 & 0 & 0 \\
\hline & Total & 1 & 1 & 0 & 1 & 3 \\
\hline \multirow{4}{*}{ November } & Minor & 0 & 0 & 0 & 0 & 0 \\
\hline & Significant & 0 & 0 & 0 & 1 & 1 \\
\hline & Single fatality & 0 & 0 & 1 & 0 & 1 \\
\hline & Total & 0 & 0 & 1 & 1 & 2 \\
\hline \multirow{4}{*}{ December } & Minor & 0 & 0 & 0 & 0 & 0 \\
\hline & Significant & 0 & 0 & 0 & 0 & 0 \\
\hline & Single fatality & 1 & 0 & 0 & 0 & 1 \\
\hline & Total & 1 & 0 & 0 & 0 & 1 \\
\hline \multirow{5}{*}{ Overall } & Severity & 2008 & 2009 & 2010 & 2011 & Total \\
\hline & Minor & 4 & 3 & 3 & 3 & 13 \\
\hline & Significant & 2 & 0 & 3 & 3 & 8 \\
\hline & Single fatality & 2 & 0 & 1 & 0 & 3 \\
\hline & Overall total & 8 & 3 & 7 & 6 & 24 \\
\hline
\end{tabular}


Table 5 RCOs.

\begin{tabular}{llll}
\hline RCO parameter & RCO1 & RCO2 & RCO3 \\
\hline Identification/description & Training/education program & Quality assurance system & $24-7$ monitoring system \\
Risk reduction rate (\%) & 20 & 30 & 40 \\
$\Delta C$ (\$/port) & 50,000 & 100,000 & 200,000 \\
Expected lifetime (years) & & 5 & \\
\hline
\end{tabular}

Table $6 \Delta R$ and $\Delta C / \Delta R$ for human and environmental damages.

\begin{tabular}{|c|c|c|c|}
\hline Risk parameter & RCO1 & $\mathrm{RCO} 2$ & $\mathrm{RCO} 3$ \\
\hline RCO identification/description & Training/education program & Quality assurance system & 24-7 monitoring system \\
\hline Risk reduction & $20 \%$ & $30 \%$ & $40 \%$ \\
\hline $\begin{array}{l}\text { (a) Human damage } \\
\text { (fat./port-year) }\end{array}$ & 0.982 & & \\
\hline b) Environ. damage (t/port-year) & 0.375 & & \\
\hline Expected lifetime & 5 years & 5 years & 5 years \\
\hline \begin{tabular}{|l|l|}
$\Delta R$ & a) fat./port \\
b) t/port
\end{tabular} & $\begin{array}{l}\text { a) } 0.982 \\
\text { b) } 0.375\end{array}$ & $\begin{array}{l}\text { a) } 1.473 \\
\text { b) } 0.562\end{array}$ & $\begin{array}{l}\text { a) } 1.964 \\
\text { b) } 0.750 \\
\end{array}$ \\
\hline$\Delta C(\$ /$ port $)$ & 50,000 & 100,000 & 200,000 \\
\hline$\Delta C / \Delta R$ vs. ICAF (\$/fat.) & $50,916<3,000,000$ & $67,888<3,000,000$ & $101,833<3,000,000$ \\
\hline$\Delta C / \Delta R$ vs. CATS $(\$ / \mathrm{t})$ & $133,333>60,000$ & $177,936>60,000$. & $266,667>60,000$ \\
\hline
\end{tabular}

minor impact, which were assumed to equate to a total of $1.5 \mathrm{t}$ of oil spilled, thus presenting an oil spillage rate of $0.375 \mathrm{t}$ per port-year.

\section{$3.2 R C O$}

Port expert judgment is employed in order to determine the proposed RCOs and estimate their risk reduction rate (\%), with the aim of mutually targeting towards the control of both types of risks, i.e., of human and environmental consequences.

In an exercise which could be split into two separate tasks, port expert judgment firstly proceeded with the identification of RCO and secondly with the estimation of the risk reduction rate. In the first task, experts have to collect data from previous steps and to identify the potential measures and which of them are suitable to produce a number of possible and practical RCOs. According to the aforementioned expert judgment, three distinct RCOs are proposed of increasing risk reduction rate and cost (Table 5), involving a training/educational program (RCO1), a quality assurance system (RCO2) and a 24-7 monitoring system (RCO3). These RCOs are to be applied for a period of 5 years, which represents a minimum duration of time after which any RCOs would be expected to be productive. The NPV cost of each RCO has been determined through an extensive market research and includes initial investment as well as operational expenditure over the 5 -year period.

\subsection{RCO Economic Effectiveness}

The risk reduction $(\Delta R)$ and the economic effectiveness $(\Delta C / \Delta R)$ of the three proposed RCOs for the control of human and environmental risks associated with the container terminal of Thessalonica are presented in Table 6, as follows:

\subsection{Decision Making}

All the proposed RCOs are found to be economically effective towards the control of human-related risks, whilst with regard to their prioritization RCO1 is the most effective and $\mathrm{RCO} 3$ the least effective. On the contrary, none of the RCOs are found to be economically effective for the control of the environmental risk, although RCO1 is closest in satisfying the CATS criterion and $\mathrm{RCO} 3$ the most distant. It should be noted at this point that the risk reduction rate for each of the proposed RCOs is considered to be equally applicable to human and environmental risks. As shown in Table 7, the application 
Table 7 Port risk matrix and index.

\begin{tabular}{lllll}
\hline Frequency/severity & Minor & Significant & Severe & Catastrophic \\
\hline Frequent & 5 & 6 & 7 & 8 (highest $P R I$ ) \\
Reasonable possible & 4 & 5 & 6 & 7 \\
Remote & $3 \leftarrow \leftarrow 2$ & 5 & 6 \\
Extremely remote & 1 (lowest $P R I)$ & 3 & 4 & 5 \\
\hline
\end{tabular}

of an RCO will not only lower the risk level from " 6 " to "3" depending on the RCO influence upon the frequency and/or the severity of the risk, but it will do so in the most economically effective manner. In this manner, port safety risk levels expressed through an industry agreed and standardized $P R I$ will facilitate the ranking of the safety-cost function amongst various ports of similar specialization (e.g., container terminals) and will also provide a benchmark for self-improvement.

\section{Conclusions}

The proposed PRA methodology builds its structure and functionality in accordance with the FSA and is adapted through the utilization of port expert judgment and existing topical literature in order to tailor its applicability within the port domain. The empirical case study of the container terminal of Thessalonica in Greece provided a workable example through which the reliability of the proposed PRA was demonstrated and the factors affecting the economic effectiveness of proposed RCOs were highlighted. The proposed PRA methodology needs to be tested in other container terminals in Greece, across Europe and other continents, as well as in other port segments, such as passenger, car and cruising terminals in order to detect how their operational particularities may affect their existing risk profile and subsequently its control.

\section{References}

[1] Berle, O., Asbjørnslett, B. E., and Rice, J. B. 2011. "Formal Vulnerability Assessment of a Maritime Transportation System.” Reliability Engineering \& System Safety 96 (6): 696-705.

[2] Chlomoudis, C. I., and Pallis, L. P. 2008. "Defining Factors for the Undertaking of Risk for Investments in the Port Industry.” Presented at the International Association of Maritime Economists (IAME) Conference 2008, Dalian, China.

[3] Chlomoudis, C. I., Kostagiolas, P. A., and Lampridis, D. C. 2005. "Prospective Employment of Quality Awards in the Seaport Industry: Old Solution to Contemporary Questions.” Presented at the International Association of Maritime Economists (IAME) Conference 2005, Limassol, Cyprus.

[4] Chlomoudis, C. I., Kostagiolas, P. A., and Pallis, L. P. 2012. "An Analysis for Formal Risk and Safety Assessments for Ports: Empirical Evidence from Container Terminals in Greece.” Journal of Shipping and Ocean Engineering 2 (1): 45-54.

[5] Chlomoudis, I. C., Lampridis D. C., and Pallis, L. P. 2013. "Quality Assurance: Providing Tools for Managing Risk in Ports." International Journal of Maritime, Trade and Economic Issues 1 (1) 3-20.

[6] Kontovas, C. A., Psaraftis, H. N., and Ventikos, N. P. 2010. “An Empirical Analysis of IOPCF Oil Spill Cost Data." Marine Pollution Bulletin 60:1455-66.

[7] Psarros, G., Skjong, R., Endersen, O., and Vanem, E. 2009. A Perspective on the Development of Environmental Risk Acceptance Criteria Related to Oil Spills. Annex to International Maritime Organization document MEPC 59/INF.21, submitted by Norway.

[8] Ronza, A., Lazaro-Touza, L., Carol, S., and Casal, J. 2009. "Economic Valuation of Damages Originated by Major Accidents in Port Areas.” Journal of Loss Prevention in the Process Industries 22: 639-48.

[9] Skjong, R., Vanem, E., and Endresen, O. 2005. Risk Evaluation Criteria, SAFEDOR-D-4.5.2-200710-24-DNV-RiskEvaluationCriteria-rev-3.0. Accessed November 22nd, 2012. http://www.safedor.org.

[10] Trbojevic, V. M., and Carr, B. J. 2000. "Risk Based Methodology for Safety Improvements in Ports.” Journal of Hazardous Materials 71: 467-80.

[11] Trucco, P., Cagno, E., Ruggeri, F., and Grande O. 2007. “A Bayesian Belief Network Modelling of Organisational Factors in Risk Analysis: A Case Study in Maritime Transportation.” Reliable Engineering and System Safety 3: 22-34.

[12] Vanem, E., Endresen, O., and Skjong, R. 2007a. "Cost Effectiveness Criteria for Marine Oil Spill Preventive Measures.” Reliability Engineering and System Safety 93 (9): 1354-68.

[13] Vanem, E., Endresen, O, and Skjong, R. 2007b. 
Port Container Terminal of Thessalonica, Greece

"CATS - Cost-Effectiveness in Designing for Oil Spill Prevention." Presented at PRADS 2007 Conference, Houston, USA.
[14] Yamada, Y. 2009. "The Cost of Oil Spills from Tankers in Relation to Weight of Spilled Oil.” Marine Technology 46 (4): 219-28. 